\title{
Los mecanismos de salida de las inversiones en el mercado de capital privado (private equity) y la experiencia peruana
}

Aldo Reggiardo Denegri

Abogado por la Pontificia Universidad Católica del Perú. Máster en Derecho (LL.M) por la Universidad de Nueva York.

SUMARIO:

I. Introducción.

II. Etapas de la inversión de capital privado.

III. La desinversión:

1. Cláusulas de salida incluidas en los contrato de inversión de capital privado para proteger la salida de la inversión realizada;

1.1. Derechos de arrastre (Drag along rights)

1.2. Derechos de arrastre (Drag along rights)

1.3. Derechos de opción de venta de acciones a otros socios de la sociedad objetivo (buy-back clauses)

2. Formas habituales de salida de las inversiones de capital privado:

2.1. Trade Sales;

2.2. Venta a otro fondo o inversionista de capital privado;

2.3. Derecho de rescate;

2.4. Salida a través del mercado secundario.

3. La salida de la inversión de capital privado en el mercado peruano:

3.1. La breve experiencia peruana;

3.2. Los probables escenarios a futuro.

3.2.1. Ventas estratégicas (trade sales).

3.2.2. Transferencias a otros fondos de capital privado 


\section{INTRODUCCIÓN}

En mercados de mayor desarrollo que el nuestro la industria de private equity o de capital privado'es el corazón de las actividades de finanzas corporativas y de fusiones y adquisiciones ${ }^{2}$; $y$ sin duda jugará un rol importante en el mercado peruano acompañando el crecimiento económico que viene experimentando el país en la última década.

La esencia de esta industria puede resumirse en el capitalismo más puro, en el que la maximización de los recursos y la creación del mayor valor posible de la inversión realizada son los estandartes de la misma.

Esta industria en donde la habilidad financiera, la visión y la ejecución de objetivos predeterminados se complementan, encierra una paradoja en su esencia. Es una industria en la que los gestores de los fondos de inversión de capital privado tienen como misión inmediata invertir los fondos tomados del mercado de inversionistas, en empresas que no coticen en una bolsa de valores, pero al mismo tiempo conviven con la presión de tener que pensar en la salida más eficiente, segura y rentable para la inversión que se realice, pues el plazo para devolver la misma tiene un término definido en el tiempo.

Es una industria que desde la óptica de los gestores de fondos de inversión y de los aportantes de recursos a éstos, resulta siendo eminentemente financiera, en donde las inversiones son temporales y con proyección de obtener los mayores retornos posibles en el mercado en el que se realicen.

En esta medida, como quiera que las inversiones de capital privado se canalizan a través de la adquisición de acciones o participaciones de empresas no cotizadas, dichas inversiones se configuran como una estrategia de inversión por parte de los inversionistas, toda vez que permite a éstos diversificar su portafolio de inversiones en instrumentos de renta variable (acciones y participaciones) de empresas no cotizadas en mercados secundarios. Por ello, son inversiones poco líquidas y por tanto nunca inversiones de corto plazo.

Así las cosas, la clave del éxito para el inversionista interesado en canalizar sus excedentes a través de un fondo de capital privado es evaluar de forma objetiva y desapasionada la capacidad y experiencia de los administradores de los fondos, siendo este componente crucial para que se obtengan resultados favorables en las inversiones a ser realizadas.

Por ello, el track record, la capacidad y la experiencia en la industria de los gestores de fondos de inversión son variables fundamentales de análisis a efectos de decidir canalizar sus excedentes a través de tal o cual fondo de inversión.

Decidida la inversión y siendo esperable un retorno respecto de la misma, al ser inversiones que se efectúan en empresas no cotizadas en mercados secundarios ${ }^{3}$, la salida de dichas inversiones configura una de las principales fuentes de preocupación de los gestores de inversión de fondos de capital privado.

Los compromisos de retorno de las inversiones realizadas a los inversionistas por parte de los gestores y la devolución del monto invertido, así como la entrega de la rentabilidad esperada en un plazo determinado, ponen de manifiesto la preocupación por parte de los gestores de los fondos de inversión respecto de aquellos mecanismos y alternativas que permitan efectuar la desinversión en el momento adecuado, de la manera más rápida, segura y eficiente posible.

1. En el presente artículo se utilizan como sinónimos, e indistintamente, el término castellano "capital privado" y el término inglés "private equity".

2. BICKLE, Justin. The place of private equity in the corporate finance and M\&A. En: Private Equity: A Transactional Analysis. Globe Business Publishing Ltd. 2007. p. 11

3. Los mercados secundarios permiten dotar de liquidez inmediata a las inversiones. 


\section{ETAPAS DE LA INVERSIÓN DE CAPITAL PRIVADO}

Las etapas o estadios por los que pasa una inversión de capital privado pueden ser graficadas de la siguiente manera ${ }^{4}$ :

Como se puede apreciar, a diferencia de otras operaciones de compra y venta de empresas en las cuales la vocación del inversionista o adquirente es la de permanencia en la sociedad adquirida, en las operaciones de compra de participaciones de capital que involucran una operación de private equity el ciclo de vida de la inversión es circular, en la medida que la inversión efectuada retorna al mismo lugar del que se originó en un plazo determinado, siendo su vocación eminentemente temporal.

Dicho ciclo tiene un punto de inicio que se da con el "levantamiento" de fondos en el mercado de inversionistas. Un segundo estadio involucra la identificación y análisis de las oportunidades de inversión, lo que implica la identificación de potenciales sociedades objetivo receptoras de la inversión. Luego viene el acto de inversión propiamente dicho a través de la adquisición de acciones o participaciones sociales de la empresa objetivo ${ }^{5}$.

Posteriormente a que se haga efectiva la inversión se da una etapa de meseta que tiene que ver con la gestión del negocio adquirido por medio de la inversión realizada, o de relacionamiento con los controladores de la empresa objetivo en aquellos supuestos en los cuales no se hubiese adquirido una participación que otorgue el control de la empresa objetivo.

Sigue a esta etapa una de evaluación de los distintos escenarios de salida de la inversión realizada; y finalmente la última etapa que configura aquel escenario en el que se da la desinversión de los recursos de la empresa objetivo y la posterior devolución de los montos obtenidos con la correspondiente ganancia, de ser este el caso, a los inversionistas.

Las inversiones de capital privado tienen un ciclo de vida, y tal ciclo puede ser graficado desde el primer momento en que se realiza la inversión hasta el punto esperable de retorno de

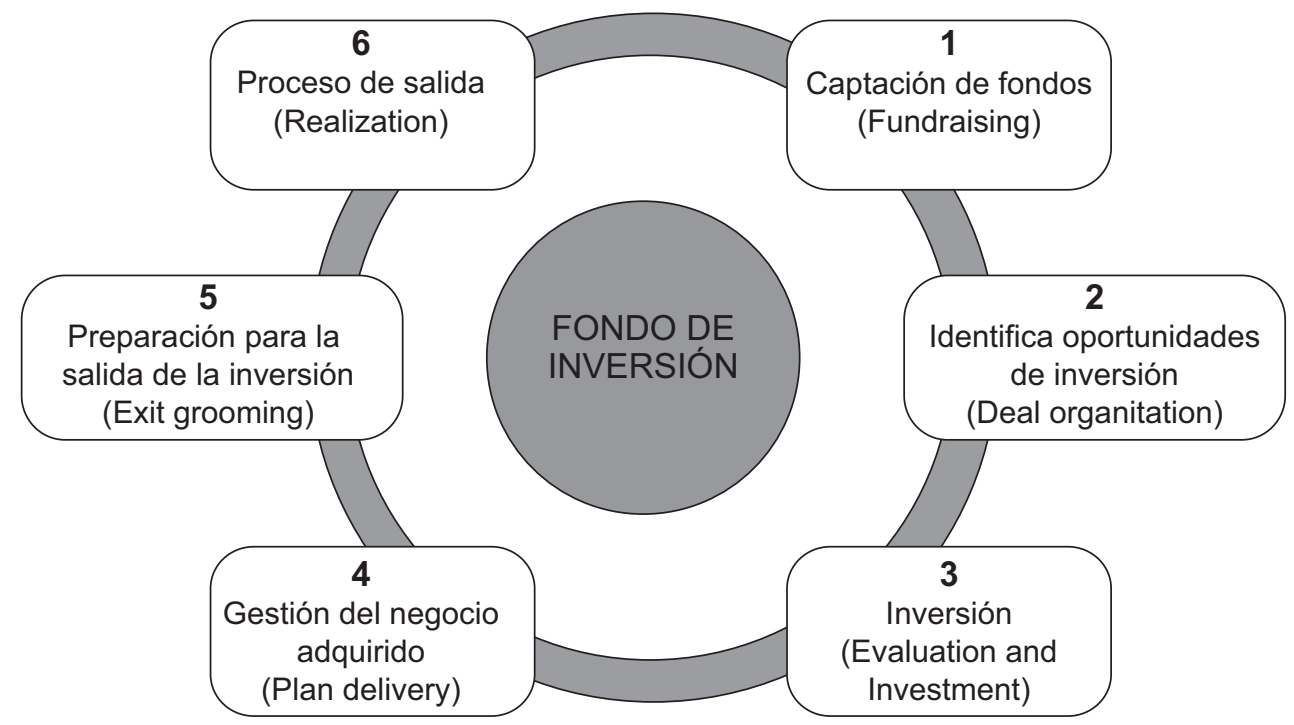

4. Fuente: www.kpmg.com/privateequity.

5. Nótese que si bien la fórmula típica de las operaciones de capital privado es aquella por la cual se compran acciones o participaciones de una sociedad objetivo determinada, existen diversas alternativas a través de las cuales se puede llegar a realizar una inversión de capital privado. 
la inversión que marca el fin de la misma y trae como consecuencia la desinversión de la empresa objetivo. Tal situación suele ser graficada a través de la "Curva J" que muestra todo el ciclo de la inversión de private equity".

Es en esta última etapa, la de desinversión, en la que nos centraremos en lo que sigue del presente trabajo.

\section{LA DESINVERSIÓN}

Definida como aquella situación en la que se hace líquida la inversión de capital privada realizada. La etapa de salida es una de las más importantes de todo el ciclo de vida de una inversión de capital privado.

La salida de una inversión de esta naturaleza encierra un riesgo implícito que es la eventual falta de alternativas para dotar de liquidez a la inversión efectuada. Es por ello que en la estructuración de una inversión de capital privado se suelen establecer cláusulas y estipulaciones contractuales que protegen la posibilidad de salir de la inversión realizada en distintos escenarios.
Las estipulaciones contractuales para regular este tipo de situaciones y que se contemplan en los acuerdos de inversión, son conocidas en la industria como eventos de liquidez.

En lo que sigue se desarrollan las cláusulas principales para regular supuestos de desinversión, las formas usuales en las que se produce la desinversión y un análisis breve del mercado local de salida de las inversiones efectuadas por los fondos de private equity.

\section{Cláusulas de salida incluidas en los contrato de inversión de capital privado para proteger la salida de la inversión realizada}

Como lo indica el título de este acápite estas cláusulas tienen por objetivo proteger la finalidad última de la inversión de capital privada cual es obtener la máxima rentabilidad posible de la inversión a través de su salida del capital de la empresa objetivo en un plazo previamente predeterminado, siempre dependiendo de las circunstancias del mercado y de las oportunidades de salida que se puedan presentar durante el plazo de la inversión.

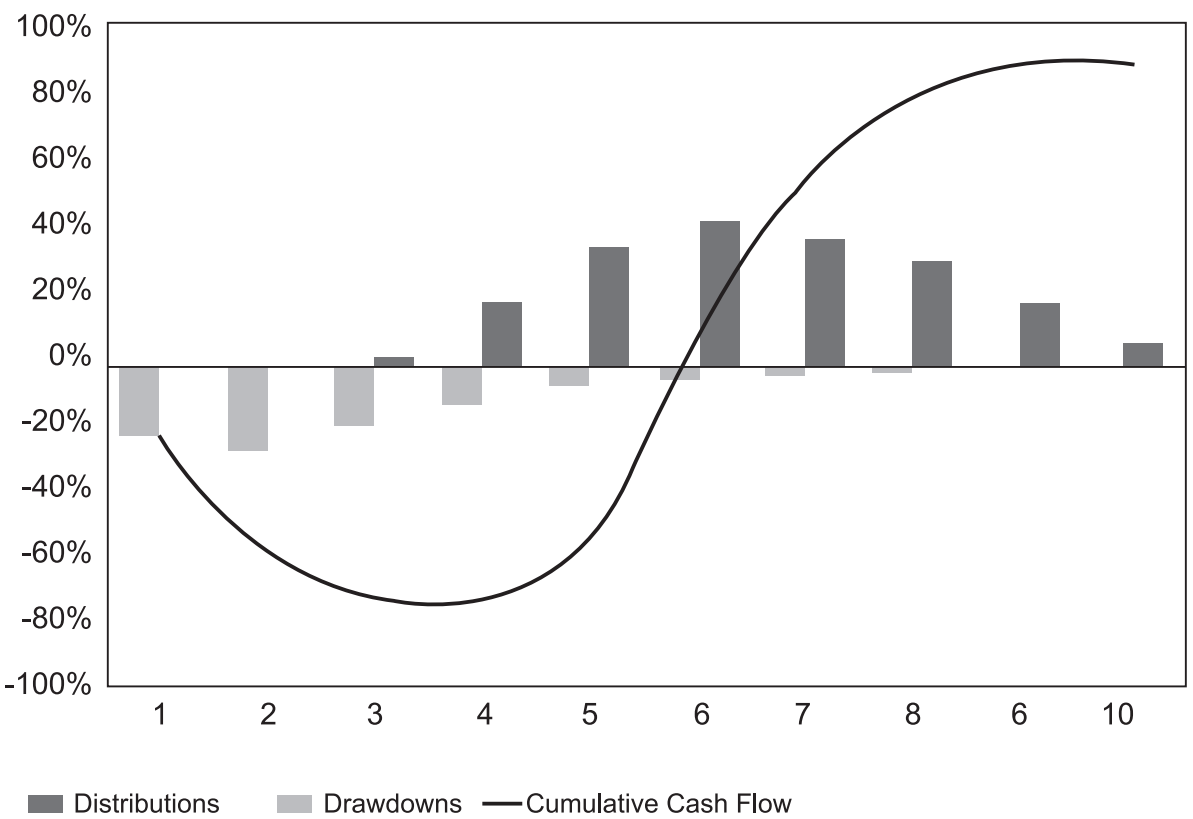

6. Fuente : www.venturechoice.com 
En esa línea, los contratos de inversión que regulan el ingreso de los fondos de inversión de capital privado a una determinada sociedad target suelen contener cláusulas que regulan y protegen la posición del inversionista de capital privado frente a la ocurrencia de un evento de liquidez.

Entre las cláusulas comúnmente adoptadas en los acuerdos de inversión para efectos de regular la salida de una inversión están las siguientes:

\subsection{Derechos de arrastre (Drag along rights)}

Este derecho, como es conocido, busca dotar al accionista que quiere vender su participación accionaria con el derecho de forzar la venta de la participación accionaria del resto de accionistas de la sociedad, para efectos de lograr una venta del $100 \%$ de las acciones o participaciones sociales emitidas por la sociedad objetivo si es que se recibe una oferta por ese porcentaje del capital social o por un porcentaje menor, según fuere el caso.

Como podrá imaginarse, la alternativa para el socio inversionista de capital privado de poder lograr indirectamente la venta a un tercero del $100 \%$ de las acciones de la sociedad objetivo representa una ventaja de valor en la medida que los adquirentes de control de una sociedad están siempre dispuestos a pagar una prima por el control que difícilmente asumirían si el porcentaje de acciones vendido por el inversionista de capital privado no fuera suficiente para asegurarles el control de la sociedad que se pretende adquirir.

Así, este derecho fuerza un escenario de salida ideal para el accionista de capital privado y por ello la negociación de este tipo de cláusulas es altamente demandada por los inversionistas de private equity, sea que cuenten con la mayoría de las acciones o participaciones de la sociedad objetivo, o sean solo accionistas o socios minoritarios de la misma.

En el primero de dichos escenarios, la oferta de un tercero interesado en adquirir la sociedad objetivo en su totalidad hará posible que tal objetivo se concrete de contarse con este tipo de cláusulas. En el segundo, teniendo una posición minoritaria el inversionista de capital privado logrará obtener un mayor valor por su inversión pues tendrá siempre acceso a la prima de control de la sociedad objetivo no obstante no ser titular de la misma como socio o accionista. Logrando indirectamente un resultado al que no podía acceder directamente.

A efectos de dotar de eficacia jurídica al derecho de arrastre es común que en la estructuración de los contratos de inversión se establezca un poder irrevocable, o se suscriba un mandato sujeto a condición suspensiva, a favor del titular del derecho. Los efectos de dicho poder o mandato solo surtirán efecto en el momento en el que se reciba una oferta de compra para adquirir las acciones o participaciones sociales de la sociedad objetivo, en las condiciones convenidas previamente por las partes para dotar de efectos a la cláusula de arrastre.

En este escenario, recibida una oferta de un tercero, el inversionista de capital privado titular del derecho de arrastre, podrá disponer válidamente de las acciones o participaciones sociales del resto de accionistas de la sociedad objetivo transfiriéndolas al tercero ofertante, conjuntamente con su paquete accionario, ello en aplicación de la cláusula de drag-along pactada.

\subsection{Derechos de acompañamiento (Tag along rights)}

Este tipo de estipulación contractual otorga a los socios o accionistas que no están participando en una eventual transferencia de las acciones de la sociedad objetivo la facultad de plegarse y acompañar al que haya decidido transferir sus acciones, permitiendo de esta forma que sus acciones o participaciones sociales sean transferidas conjuntamente con el paquete accionario del socio o accionista vendedor.

Normalmente será un derecho establecido en interés de los socios o accionistas originales de la sociedad objetivo, que querrán tener acceso a cierta liquidez adicional y que mantienen interés 
en aprovechar la circunstancia de ser accionistas conjuntamente con un fondo de inversión que, lógicamente, será quien por su red de contactos y experiencia tenga la capacidad de conseguir mejores oportunidades de venta de sus acciones ${ }^{7}$.

No obstante lo anterior, no es extraño que los inversionistas de capital privado soliciten que se les otorgue este derecho de acompañamiento de manera recíproca. Tal derecho es exigido a efectos de cautelar la posibilidad de salir de la inversión por lo menos parcialmente en el caso que los otros accionistas de la sociedad objetivo reciban una oferta de compra por sus acciones o participaciones sociales.

Las cláusulas de acompañamiento suelen pactarse por el todo o a prorrata en función del porcentaje de cada uno de los accionistas en el capital social. Así, en este último escenario el comprador adquirirá el número de acciones que quiso adquirir originalmente pero no todas del mismo vendedor sino de dos o más vendedores distintos. El destinatario original de la oferta, y él o los accionistas que hicieron uso del derecho de acompañamiento, en los porcentajes que a cada uno corresponda en el capital social de la sociedad emisora de las acciones o participaciones que se desee transferir.

Debe tenerse en consideración que el proceso de ejercicio del derecho de acompañamiento puede ser muy farragoso, tanto que podría retrasar una operación de compra de acciones o participaciones y en el extremo frustrarla. Es por ello que algunas veces se suele establecer un mecanismo contractual en virtud del cual se dispone que el receptor de la oferta de compra pueda transferir sus acciones al tercero oferente, sin pasar por el proceso de ejercicio del tag-along pero que, para efectos de no vulnerar los derechos de aquellos accionistas o socios respecto de los cuales se estableció el derecho de acompañamiento, se deba depositar en una cuenta bancaria el monto que les hubiera correspondido de la transferencia a los accionistas o socios de haber ejercido el derecho de acompañamiento. Dicho depósito se fija por un plazo determinado, durante el cual los titulares del tag-along serán notificados para que ejerzan la potestad de transferir o no sus acciones o participaciones haciendo ejercicio de su derecho de acompañamiento, luego de lo cual, si ejercen el derecho y suscriben la documentación que corresponda para transferir las acciones, el dinero puede ser liberado de la cuenta bancaria a su favor, y si deciden no ejercerlo, el depósito dinerario es restituido al depositante original ${ }^{8}$.

\subsection{Derechos de opción de venta de acciones a otros socios de la sociedad objetivo (buy-back clauses)}

Como se ha señalado precedentemente el interés del inversionista de capital privado reside en liquidar su inversión rentabilizándola en el mayor valor posible. En el hipotético escenario en que la inversión realizada pueda resultar siendo poco exitosa, el inversionista de capital privado suele incorporar cláusulas en los contratos de inversión que vinculen a los otros accionistas de la sociedad objetivo con su inversión.

La idea que subyace en este tipo de escenario es proteger al capital invertido originalmente, dotando al inversionista de capital privado de una opción de venta de sus acciones o participaciones frente al resto de accionistas de la sociedad objetivo.

En ese sentido, una forma habitual que se utiliza para estructurar la salida de una inversión de capital privado que garantice un piso mínimo de rentabilidad a la inversión que se realice, es a través de establecer la compra compulsoria de las acciones o participaciones de los accionistas o socios de capital privado a los otros socios o accionistas de la sociedad objetivo.

7. ERLAIZ COTELO, Înigo. Las etapas de la inversión y su regulación contractual en los distintos tipos de operación (buyouts y capital de desarrollo). En: Capital de Riesgo (Private Equity) Aspectos regulatorios, mercantiles, financieros, fiscales y laborales. Thomson Aranzadi. 2006. p. 437

8. ERLAIZ COTELO, Íñigo. Op. Cit. p.440 
A través de estas cláusulas lo que se pretende es que los accionistas o socios de la sociedad objetivo, distintos a los inversionistas de capital privado, tengan la obligación de readquirir las acciones o participaciones sociales que vendieron en un primer momento, a un determinado precio; cuando los inversionistas decidan ejercer la opción de vender sus acciones o participaciones sociales, "liquidando" de esta forma su participación en la empresa target.

De esta forma, la inversión de capital privado no sólo está protegida si es que la empresa objetivo no tiene éxito sino también en el supuesto que el éxito esperado por los inversionistas no se produzca en la práctica.

No obstante lo positivo que podría resultar a priori para el inversor de capital privado conseguir este tipo de cláusulas en las negociaciones conducentes a adquirir una participación determinada de la empresa objetivo, su efectividad final puede ser cuestionada en la medida que los obligados por la cláusula de recompra, en un escenario de poco éxito del negocio de la empresa objetivo, pueden no contar - en la mayoría de casos- con los recursos suficientes para adquirir las acciones que se encuentran obligados a adquirir contractualmente, dado que los mismos provienen de los resultados de la empresa objetivo de la cual el accionista o socio de capital privado pretende salir.

Evidentemente resulta improbable que se presente tal situación bajo un escenario de bonanza económica de la empresa objetivo. Escenario en el cual resulta poco probable que se percuta la cláusula de buy-back al ser altamente probable que exista un mercado para el paquete accionario del que se pretende desprender el accionista de capital privado.

En línea de lo anterior, resulta primordial estructurar este tipo de cláusulas de manera tal que permitan su eficacia práctica a través del otorgamiento de poderes irrevocables o mandatos al inversionista de capital privado que lo faculten a ejecutar la opción y además garantizar el pago del precio preestablecido a través de garantías personales y reales - las propias acciones de la so- ciedad de titularidad de los obligados con el pacto de buy-back-. Ello a efectos de que en la práctica este tipo de estipulaciones no resulten siendo letra muerta en el contrato de inversión suscrito entre los accionistas de la sociedad objetivo.

Nótese adicionalmente, que la cláusula de recompra o de opción de venta a los socios o accionistas no inversionistas puede encerrar una suerte de cláusula drag-along indirecta, cuando dicha cláusula no se hubiese conseguido originalmente. ¿Cómo así? Imaginemos un escenario en el cual hay un comprador interesado en adquirir el control de una compañía, control que no ostenta el accionista de inversión, pero éste está interesado en salir de su inversión mediante la oferta presentada y cuenta con una cláusula de recompra de sus acciones frente al resto de accionistas. Así las cosas, en caso la oferta fuese inferior en valor a la opción de recompra que tiene el accionista de inversión, pero aún así resulte atractiva en el momento en que se realice para el inversionista de capital privado, puede éste plantearle al resto de accionistas que acepten la oferta del tercero, o de lo contrario ejercerá el buy-back, con lo cual estaría forzando de manera indirecta la aplicación de un dragalong respecto de la oferta planteada.

\section{Formas habituales de salida de las inversiones de capital privado}

\subsection{Trade sales}

Una de las formas usuales a través de la cual se suele hacer líquida una inversión de capital privado, es a través de la transferencia de la sociedad objetivo (o por lo menos de las acciones o participaciones sociales del socio inversionista) a un tercero adquirente (inversionista estratégico) que esté interesado en dicha empresa con interés de hacerse del control de la misma, o con una participación de ésta, no por razones de inversión financiera sino de expansión, consolidación, integración horizontal, o de búsqueda de sinergias por medio de la adquisición que pretende realizar.

En mercados más desarrollados que el nuestro, las trade sales o salidas a través de trans-

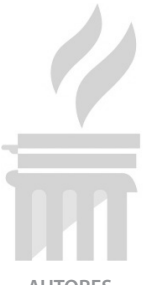
AUTORES
NACIONALES 
ferencias a inversionistas estratégicos suelen ser vistas como second best way out ${ }^{9}$ para las inversiones de capital privado frente a la posibilidad de hacer líquida la inversión por medio de una venta de su paquete accionario en el mercado secundario. Pero en mercados como los nuestros en el que el desarrollo de un mercado de ofertas públicas de venta (OPV) y de ofertas de venta iniciales (IPO) es aún incipiente, sin duda que este tipo operaciones son la principal fuente de salida con la que cuentan los gestores de fondos de inversión de capital privado.

La fortaleza de un trade sale exitoso, frente a la salida vía mercado secundario, consiste fundamentalmente en obtener un premio mayor en el precio de la transferencia y la posibilidad para el inversionista de capital privado de desprenderse de su inversión a través de una operación sustancialmente menos costosa y complicada, así como más rápida que una oferta pública de venta ${ }^{10}$ de su paquete accionario a través del mercado de valores.

El network y la red de contactos de los gestores de fondos de inversión resultan en este escenario fundamentales para efectos de lograr alternativas de salida a través de ventas a inversionistas estratégicos.

\subsection{Venta a otro fondo o inversionista de capital privado}

Esta fórmula de salida de una inversión de capital privado consiste fundamentalmente en la transferencia del paquete accionario del inversionista de capital privado a otro fondo de inversión que tenga interés en realizar una inversión financiera en la sociedad objetivo.

Este tipo de salidas se producen normalmente en mercados en los que la sofisticación de los fondos es alta lo que permite que coexistan fondos con diferentes perfiles de riesgo en función del estadio de desarrollo y crecimiento en el que se encuentre la sociedad objetivo. Así por ejemplo, no sería extraño ver que un fondo de inversión determinado venda su participación en una determinada empresa a otro fondo según el ciclo de vida económica en el que se encuentre la empresa objetivo.

En esa línea, un determinado fondo de inversión especializado en invertir en la etapa inicial o start-up de un negocio podría sentirse absolutamente cómodo en salir de su inversión en el momento en que la empresa comience a crecer y cumpla los objetivos originalmente previstos en su plan de negocios.

En ese particular escenario un fondo de inversión especializado en la expansión de negocios podría adquirir la participación accionaria de fondo especializado en start-ups con el objeto de llevar a ésta a un nivel de crecimiento económico distinto y buscar salir de su inversión a través de una venta a un inversionista industrial vía una trade sale o por medio del listado de las acciones de la compañía en el mercado secundario.

Existen determinadas condiciones para que exista un mercado de transferencias entre fondos de inversión de capital privado: (i) una fuerte red de contactos que permita identificar fondos de inversión con potencialidad de ser adquirentes de una participación determinada; (ii) un mercado en el que existan fondos especializados en invertir en distintos ciclos de la vida de una empresa, (iii); accionistas originales de la empresa objetivo que estén de acuerdo en seguir teniendo a fondos de inversión de capital privado como accionistas; y (iv) existencia de empresas objetivos con un plan de negocios definido para convertirse de empresa pequeñas a empresas medianas o grandes en el mediano plazo ${ }^{11}$.

9. BLOOMFELD, Stephen. Venture Capital Funding: A Practical Guide to Raising Finance. Kogan Page Limited. Second Edition 2008. p. 208.

10. CASELLI, Stefano. Private Equity and Venture Capital in Europe. Elsevier Ltda. 2010. p. 162.

11. CASELLI, Stefano. Op cit. p. 163 


\subsection{Derecho de rescate}

Por medio de esta figura lo que se pretende es dotar de salida a la inversión a través de la venta de las acciones adquiridas en la sociedad objetivo a la propia sociedad emisora de las acciones.

No obstante esta forma de salida de una inversión es una alternativa dentro de la baraja de posibilidades de desinversión, las diversas limitaciones que establecen la mayoría de las legislaciones de tradición continental con respecto de la adquisición de acciones de propia emisión por la sociedad emisora de las mismas, hace que esta posibilidad sea restringida a casos muy puntuales.

Esta alternativa de salida plantea que fijado el ingreso del inversionista de capital privado se establezca una opción de venta a su favor frente a la sociedad emisora de las acciones o participaciones en virtud de la cual en un plazo determinado y en función de determinadas variables (como por ejemplo el haber alcanzado un determinado nivel de rendimiento en las acciones adquiridas), el inversionista de capital privado puede ejercer dicha opción contra la sociedad objetivo. Esta técnica tan usual en jurisdicciones de origen anglosajón presenta problemas para implementarse en realidades como la peruana.

En particular el artículo 104 de la Ley General de Sociedades peruana establece supuestos puntuales en los cuales las sociedades pueden adquirir acciones de propia emisión con cargo a reservas libres y beneficios estableciendo que estas adquisiciones deben producirse a prorrata entre todos los accionistas salvo que se adquieran para evitar un grave daño a la sociedad, se adquieran a título gratuito, o la adquisición se haga en rueda de bolsa, o se acuerde por unanimidad en junta general otra forma de adquisición, o se traten de casos previstos en los artículos 238 y 239 de dicha norma.
Como se podrá apreciar estructurar está opción de venta a favor del inversionista de capital privado en términos que resulten razonables para las necesidades de éste requerirá, de antemano, del acuerdo de todos los accionistas reunidos en la junta correspondiente donde se trate este asunto para que la sociedad ante el ejercicio de la opción pueda adquirir sólo las acciones del inversionista de capital privado y evitarse de esa manera la aplicación de la regla general de prorrateo.

Cabe señalar que en supuestos como estos, en los que se active una opción de venta de acciones a favor del inversionistas de capital privado será de crucial importancia los procedimientos de valuación estipulados en el contrato de inversión que prevé la opción de venta, pues resulta fundamental valuar la empresa para efectos determinar el monto a pagar por la sociedad al inversionista correspondiente. Es por ello que las disposiciones de valuación deben estructurarse cuidadosamente a fin de complementar las estrategias de salida sin crear conflictos con éstas.

\subsection{Salida a través del mercado secundario}

Por intermedio de este tipo de cláusulas lo que se pretende es otorgar al inversionista de capital privado del derecho a exigir a la sociedad objetivo que registre las acciones de su propiedad en un mercado secundario y que éstas sean transferidas de forma prioritaria en una oferta pública de venta frente a cualquier otro paquete accionario de la sociedad - registration rights-.

Adicionalmente este derecho de solicitar el registro de un paquete accionario por parte de los inversionistas de capital pagado, viene acompañado de las denominadas cláusulas piggyback registration rights, que en la práctica obligan a la sociedad objetivo a registrar las acciones de los inversionistas de capital privado en caso se decida registrar acciones de cualquier otro accionista de la sociedad ${ }^{12}$.

12. Para profundizar sobre el tema de los derechos de registro en la contexto de operaciones de capital de riesgo o de capital privado recomendamos revisar Equity Finance Venture Capital, Buyouts, Restructurings and Reorganizations. BARLETT, Joseph W. (Aspen Publishers, Second Edition). 
Con los derechos de registro lo que se busca es que se produzca la coexistencia en la práctica de una IPO de acciones con una OPV, ésta última respecto del paquete accionario del inversionista de capital privado.

En la estipulación de este mecanismo de salida se prevé, por lo general, que sea el inversionista de capital privado quien tenga el derecho unilateral a decidir en qué momento sus acciones serán objeto de una OPV ${ }^{13}$.

En ese orden de ideas, a efectos de hacer viable este tipo de cláusulas es usual que de antemano las acciones del inversionista de capital privado se configuren en una clase de acciones particular - acciones que podrán ser objeto de la oferta pública de venta- y que adicionalmente se asuma el compromiso firme de la sociedad objetivo, y del resto de accionistas de dicha sociedad, de realizar todos aquellos actos y acuerdos societarios que resulten necesario a efectos de llevar a cabo la venta de dicho paquete accionario a través del mercado secundario en la eventualidad que se haga ejercicio de la cláusula de registro de las acciones.

En esa misma línea, los acuerdos de registro de acciones suelen estar acompañados con acuerdos que establecen lock-up periods a efectos de evitar que los accionistas de la sociedad objetivo que sean titulares del control o de un número significativo de las acciones de la sociedad target puedan vender sus acciones por un plazo determinado de tiempo, con la finalidad de evitar que una venta masiva de acciones de la compañía pueda afectar el valor de las acciones de la empresa objetivo dentro del marco de una oferta inicial de acciones.

En alguna medida este tipo de disposiciones también protege el valor de la inversión del inversionista de capital privado en la medida que una venta en bloque de las acciones de control de la sociedad puede acarrear una depresión en el valor de las acciones cotizadas en bolsa perjudicando la salida a un valor razonable del accionista de capital privado.

Los acuerdos de lock-up periods en el contexto de una IPO suelen servir, a su vez, como una señal al mercado por parte de los actuales accionistas de la sociedad emisora, de modo tal, que no se interprete erróneamente que la emisión de acciones se debe a una mala situación financiera o de poca rentabilidad de la sociedad objetivo.

De igual forma es usual que se adopten acuerdos conducentes a eliminar toda restricción a la transferencia de acciones $y$, en algunos casos a la conversión automática de las acciones preferentes (reunidas en una clase especial) en acciones comunes para los efectos del registro de éstas y su posterior transferencia en el mercado vía una oferta pública de venta.

\section{La salida de la inversión de capital privado en el mercado peruano}

\subsection{La breve experiencia peruana}

Reconocida la dificultad legal y técnica de establecer salidas de una inversión a través de la recompra de paquetes accionarios de los inversionistas de capital privado por parte de la sociedad objetivo; lo poco habitual y contra la propia naturaleza de una inversión de capital privado que es que se liquide una inversión a través de una opción de venta contra los accionista originales, y lo utópico que representa en el corto plazo, para plazas como la peruana, pensar en salidas masivas de inversiones de capital privado a través del mercado secundario local, no sorprende que la vía habitual para la salida de inversiones de private equity en el mercado peruano hasta la fecha haya estado representada por la venta directa de paquetes accionarios a inversionistas estratégicos.

13. Nótese que tal derecho, si bien es unilateral del inversionista, puede estar sujeto a condicionantes como por ejemplo que se establezca un lock-up period para el inversionista de capital privado en el contexto de una IPO si es que éste tiene el control de la sociedad objetivo. 
No obstante la poca información pública respecto de casos de salida de inversiones de capital privado a los que se tiene acceso, el cuadro siguiente refleja de alguna manera los pocos casos de salidas exitosas de fondos de private equity de inversiones realizadas en el mercado local.

Nótese que de las seis operaciones listadas cinco de ellas han sido salidas por medio de trade sales a inversionistas estratégicos y sólo una de ellas - Exalmar S.A.A. - representa una experiencia de salida de una inversión a través del mercado secundario.

\subsection{Los probables escenarios a futuro}

A continuación se describen los escenarios probables y más frecuentes que creemos se darán en el corto y mediano plazo para las salidas de las inversiones de los fondos de private equity que actualmente operan en el mercado local.

\subsubsection{Ventas estratégicas (trade sales)}

Desde nuestra opinión este tipo de transacciones serán las que marcarán la pauta a las salidas de las inversiones de los inversionistas de private equity en el mercado local.

Ahora bien, este tipo de transacciones podrán darse fundamentalmente, desde nuestro punto de vista, dentro de las siguientes formas, aunque sin estar limitadas a éstas: (i) mediante la venta del paquete accionario, o la empresa objetivo en su conjunto en el supuesto que se hubiesen establecido cláusulas de arrastre, o se tuviese el paquete de control de la sociedad, a una empresa rival que busque incrementar su participación o cuota de mercado mediante una adquisición horizontal de un competidor, (ii) mediante la venta a una empresa que busque a través de una adquisición vertical articular y consolidar los diferentes eslabones de la cadena de producción de una determinada industria, o (iii) que dicha sociedad o paquete accionario, sea cual fuere el caso, sea adquirido por una empresa multinacional o transnacional que busque expandir su mercado de influencia al Perú sin tener que incurrir en los costos de acceso al mercado que implicaría iniciar operaciones desde cero en el territorio nacional.

\subsubsection{Transferencias a otros fondos de capital privado}

En un mercado como el peruano en el que aún no han desembarcado, o están en proceso de hacerlo, los grandes fondos de inversión de capital privado de Latinoamérica y del mundo ${ }^{14}$, y dónde el mercado de private equityes controlado básicamente por sociedades administradoras de fondos de inversión locales y por fondos de inversión internacionales de mediana envergadura, no es de extrañar que en el mediano plazo, cuando los fondos locales se encuentren en etapa de buscar

\begin{tabular}{|l|l|l|}
\hline \multicolumn{1}{|c|}{ Comprador } & \multicolumn{1}{|c|}{ Vendedor } & \multicolumn{1}{c|}{ Empresa objetivo } \\
\hline $\begin{array}{l}\text { Teva Pharmaceutical Indus- } \\
\text { tries Ltd. }\end{array}$ & $\begin{array}{l}\text { Altra Invesments } \\
\text { The Rohatyn Group }\end{array}$ & Infarmasa S.A. \\
\hline Capricorn Dorest Fund K/S & Value Investments & $\begin{array}{l}\text { Consorcio Forestal Amazóni- } \\
\text { co S.A.C. (90\%) }\end{array}$ \\
\hline Inkia Energía & Conduit Capital Partners & Edegel S.A.A. \\
\hline Odebrecht & Conduit Capital Partners & $\begin{array}{l}\text { Kuntur Transportadora de } \\
\text { Gas S.A.C. (51\%) }\end{array}$ \\
\hline $\begin{array}{l}\text { Caleta de Oro Holding Perú } \\
\text { S.A.C. - Grupo Matta }\end{array}$ & $\begin{array}{l}\text { Stafedouble SL (subsidiaria del Citigroup Ven- } \\
\text { ture Capital International - Growth Fund I) }\end{array}$ & Exalmar S.A.A. \\
\hline Marubeni & AC Capitales & Consorcio Agua Azul S.A. \\
\hline
\end{tabular}

14. De los diez principales fondos de inversión a nivel mundial según Fortune (The Black Stone Group, Kohlberg, Kravis Roberts \& Co, The Carlyle Group, Texas Pacific Group, Bain Capital,Providence Equity Partners, Apollo Advisors, Warburg Pincus; Cerberus; Thomas H. Lee) solo The Carlyle Group ha hecho su ingreso al mercado local a través de un joint venture con el Grupo Crédito. 
que hacer líquidas sus inversiones, busquen salir de éstas a través de la venta de su paquete accionario a fondos de mayor experiencia, dimensión y track record.

Las motivaciones de los fondos de inversión extranjeros de adquirir participaciones en empresas en un país en desarrollo pero con un crecimiento sostenible en el tiempo durante los últimos diez años podrían derivarse de la identificación de oportunidades de crecimiento en la sociedad objetivo no identificadas originalmente por los fondos de inversión locales; o porque consideran que con determinados ajustes al plan de negocios implementado podrían incrementar el valor de la empresa objetivo y como consecuencia lógica el valor del paquete accionario que representa la inversión de capital que estarían realizando; o porque sim- plemente la coyuntura de crisis recesiva actual que viene afrontando el mundo y en particular determinados mercados a nivel mundial cuyo crecimiento puede ser negativo en los próximos años, obligue a los gestores de fondos de inversión internacionales a redirigir su portafolio de inversiones a mercados emergentes como el nuestro a efectos de diversificar y reducir la exposición del portafolio de las inversiones que manejan a nivel internacional.

Esta modalidad de secondary buy outs puede representar una alternativa válida de salida de las inversiones de capital privado en la industria local. Con la consiguiente profesionalización de la industria peruana de private equity, que irá sofisticándose en función de competencias, de la envergadura de los montos a invertir y de la escala de cada portafolio a manejar. 